\title{
Life Cycle Impact of Rare Earth Elements
}

\author{
P. Koltun ${ }^{1}$ and A. Tharumarajah ${ }^{2}$ \\ ${ }^{1}$ CSIRO Process Science and Engineering, Gate 5, Normanby Road, Clayton, VIC 3168, Australia \\ ${ }^{2}$ EnviSolutions, 20 Galahad Crescent, Glen Waverley, Melbourne, VIC 3150, Australia \\ Correspondence should be addressed to P. Koltun; paul.koltun@csiro.au
}

Received 19 December 2013; Accepted 14 January 2014; Published 4 May 2014

Academic Editors: M. Carboneras and P. Lukac

Copyright (C) 2014 P. Koltun and A. Tharumarajah. This is an open access article distributed under the Creative Commons Attribution License, which permits unrestricted use, distribution, and reproduction in any medium, provided the original work is properly cited.

\begin{abstract}
The diverse properties of rare earth elements have seen broad and growing applications in clean energy technologies, hybrid vehicles, pollution control, optics, refrigeration, and so on. This study presents a "cradle-to-gate" life cycle assessment of the energy use, resource depletion, and global warming potential resulting from the production of rare earth elements (REEs) using the Bayan Obo rare earth operation in Inner Mongolia, China, as a representative system. The study aggregates data from the literature, LCI databases, and reasonable estimations. A novel economic value-based allocation method for the multiple coproducts of the process is proposed. It is found that four of the high priced REEs scandium, europium, terbium, and dysprosium have very high GWPs from production relative to the rest. A mass-based allocation is also provided for comparison. Impacts on immediate local environment from waste streams that can be toxic are not included in this study.
\end{abstract}

\section{Introduction}

Rare earth elements (REEs) or RE metals are technically defined as the 15 elements in the lanthanide (La) series, yttrium (Y), and scandium (Sc). Y and Sc are considered REEs since they mostly occur in the same ore deposits and have similar chemical properties. A precise classification often used in extraction is as follows [1].

(i) Light rare earth elements (LREEs): lanthanum (La), cerium $(\mathrm{Ce})$, praseodymium $(\mathrm{Pr})$, neodymium $(\mathrm{Nd})$, and promethium $(\mathrm{Pm})$.

(ii) Medium rare earth elements (MREEs): samarium $(\mathrm{Sm})$, europium $(\mathrm{Eu})$, and gadolinium $(\mathrm{Gd})$.

(iii) Heavy rare earth elements (HREEs): terbium (Tb), dysprosium (Dy), holmium (Ho), erbium (Er), thulium $(\mathrm{Tm})$, ytterbium $(\mathrm{Yb})$, lutetium $(\mathrm{Lu})$, scandium $(\mathrm{Sc})$, and yttrium $(\mathrm{Y})$.

There are about 200 known rare-earth containing mineral deposits, mostly as carbonatites spread around the world. Contrary to a lay persons' understanding, REs are not rare in natural occurrence (cerium is more abundant than tin and yttrium is more abundant than lead), though REEs have much less tendency to become concentrated in exploitable ore deposits [2], in particular HREEs. This being so, only a few mineral species, such as bastnasite, monazite, and REbearing clay, have been recovered for commercial production. Bastnasite deposits in China and the United States constitute the largest percentage of the world's rare-earth economic resources [3].

REEs possess diverse nuclear, metallurgical, chemical, catalytic, electrical, magnetic, and optical properties. This has led to ever-increasing applications, some mundane (lighter flints, glass polishing) to others that are highly specific. Examples of the latter include catalysts in petroleum refining industry, as alloying agents (used to enhance the oxidation resistance of alloys) in metallurgical processes, in glass, phosphors, optics, permanent magnets, and electronics. Emerging and potential applications include using rare earths to absorb ultraviolet light in automotive glass, corrosion protection, and metal coatings in corrosive and salty environments. Futuristic applications of REE are in high-temperature superconductivity, safe storage, and transport of hydrogen for a posthydrocarbon economy [2]. For applications of individual REEs, see [4].

Only small quantities of REEs are used in most applications, for instance, 2 to 3 grams in a 20 -watt phosphor lamp. 
However, clean energy applications such as high capacity nickel-metal hydride batteries in hybrid cars (in a thirdgeneration Toyota Prius) contain on average $\sim 0.6 \mathrm{~kg} /$ battery of $\mathrm{La}$ [5] and RE magnets for electric motors as light weight alternative to iron magnets require around $1 \mathrm{~kg}$ of $\mathrm{Nd}[6,7]$. A utility scale wind turbine, another green power source, uses more than a ton of heavy-duty and lightweight magnets, 700 pounds of which is neodymium [8]. As the worldwide implementation of clean energy and other applications increase, many studies have identified the supply of particular REEs (dysprosium, neodymium, terbium, yttrium, and europium) to be at risk in the short and medium term $[9,10]$.

China currently accounts for $95 \%$ of global production of rare earths (about $90 \%$ of REs used in the US) and domestic industry consumes about 60\% [18]. Bayan Obo mine (used as the reference site in this study) situated in Inner Mongolia is said to supply half of the total production [19]. However, this situation may change due to China's introduction of progressively reducing export quotas since 2004/2005 [5] for reasons of environmental concerns and conservation of resources [20]. This potential risk to supply may be somewhat absorbed by recycling of in-use stocks of REEs in products (an estimated 440,000 metric tons in 2007, [21]). In fact, this source can also help to reduce the impact on the environment from the production of virgin REEs.

Many environmental issues surround the production and use of REEs. REEs having similar chemical structures are difficult to separate [22] compounded by extremely low yield (net recovery from the ore at Bayan Obo is around $0.6 \%[23,24])$. Thus, apart from the electricity, acids, water, and resources expended in production, there can be huge amounts of waste that can be toxic with potential damage to the ecosystem.

One of the most important environmental issues for producers of rare earths is the problem posed by the radioactivity of thorium-containing monazite and xenotime ores. Australian monazite exports declined precipitously between 1989 and 1992 in part because of the radioactivity concern and since 1992, Rhodia, at that time the world's largest rare earth company, has used Chinese instead of Australian rare earth concentrates for production of individual rare earth oxides [25].

Other concerns of RE pollution relate contamination of the local environment. These include potential bioaccumulation in the food chain from waste or dust contamination of water ways and soil from mines when used in downstream industrial processes and in agricultural fertilisers [27, 28].

This study, with the exception of impact on the local environment, investigates the global warming impact and intensity of use of energy and resources in the production of RE oxides (REOs) and REEs. Each of the distinct stages from mining, separation of REOs, and reduction to REEs is modelled and the input of resources (energy, water, chemicals) and wastes is examined. GHG impacts and resource depletion potential are computed from the derived data.

It is the objective of this study to disseminate knowledge of the GHG and other impacts of producing REEs, in particular at this time when their application is growing and such knowledge is not readily available. Further, it is

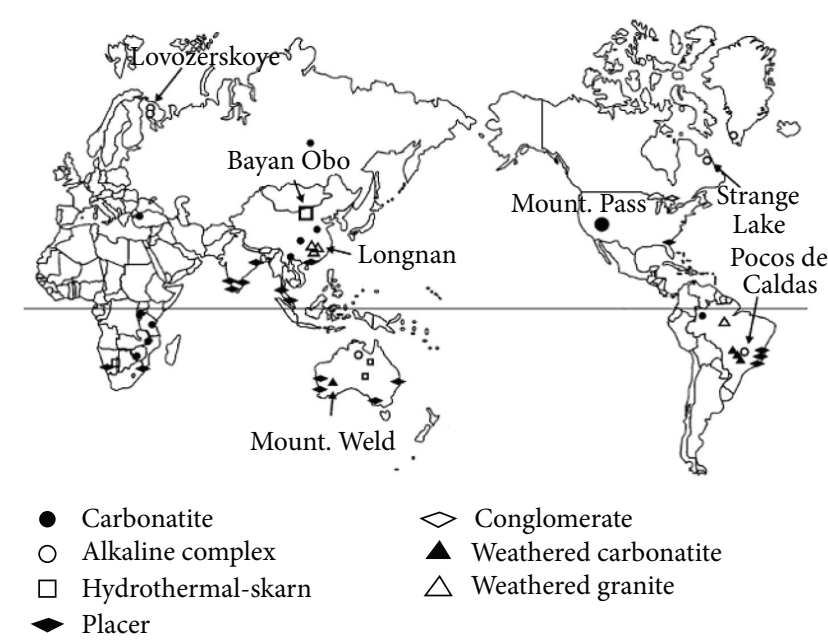

Figure 1: World distribution of rare earths [26].

believed that such data will be valuable and provide a basis for constructing and comparing GHG impact profiles of rare earth based products for comparison purposes.

\section{Extraction and Production of Rare Earths}

2.1. Sources and Distribution of Rare Earth Minerals. Only a few mineral species, such as bastnasite (a rare earth fluorocarbonate $(\mathrm{Ce}, \mathrm{La})\left(\mathrm{CO}_{3}\right) \mathrm{F}$ ), monazite (a rare earth phosphate (Ce, $\left.\mathrm{La}, \mathrm{Y} \mathrm{Th}) \mathrm{PO}_{4}\right)$ ), xenotime $\left(\mathrm{YPO}_{4}\right)$, and REbearing clay have been recovered for commercial production. Of these, bastnasites constitute the largest percentage (in US and China). Monazite deposits in Australia, Brazil, China, India, Malaysia, South Africa, Sri Lanka, Thailand, and the United States constitute the second largest segment. World distribution is shown in Figure 1. Undiscovered resources are thought to be very large relative to expected demand [3].

Around $95 \%$ of the world's rare earth metals are produced in China, and as mentioned before Bayan Obo mine supplies about half of the total production. This mine is estimated to contain at least 1.5 billion metric tons of iron (average grade $33 \%$ of iron oxide), 89 million tons of RE oxides (REOs) (average grade 6\%), and 1 million tons of niobium (average grade $0.13 \%$ ) [23]. The principal RE minerals in Bayan Obo are bastnasite and monazite accompanied by RE$\mathrm{Nb}$ minerals; further details of the geological distribution are given in [23]. This study uses Bayan Obo operations as a representative system for rare earth extraction and production. Rare earth production at Mount Pass in USA ceased operation in 2002 due to environmental concerns (production has recommenced since 2008). The projected production in 2012 is expected to be between 8,000 and 10,000 metric tons [29]. Mining at the Mount Weld deposit in Western Australia began in 2007, and an estimated 98,000 cubic meters of ore has been stockpiled awaiting the completion of a concentration plant at the mine site. The concentrates will be exported to an advanced materials plant being built in Malaysia [30]. 


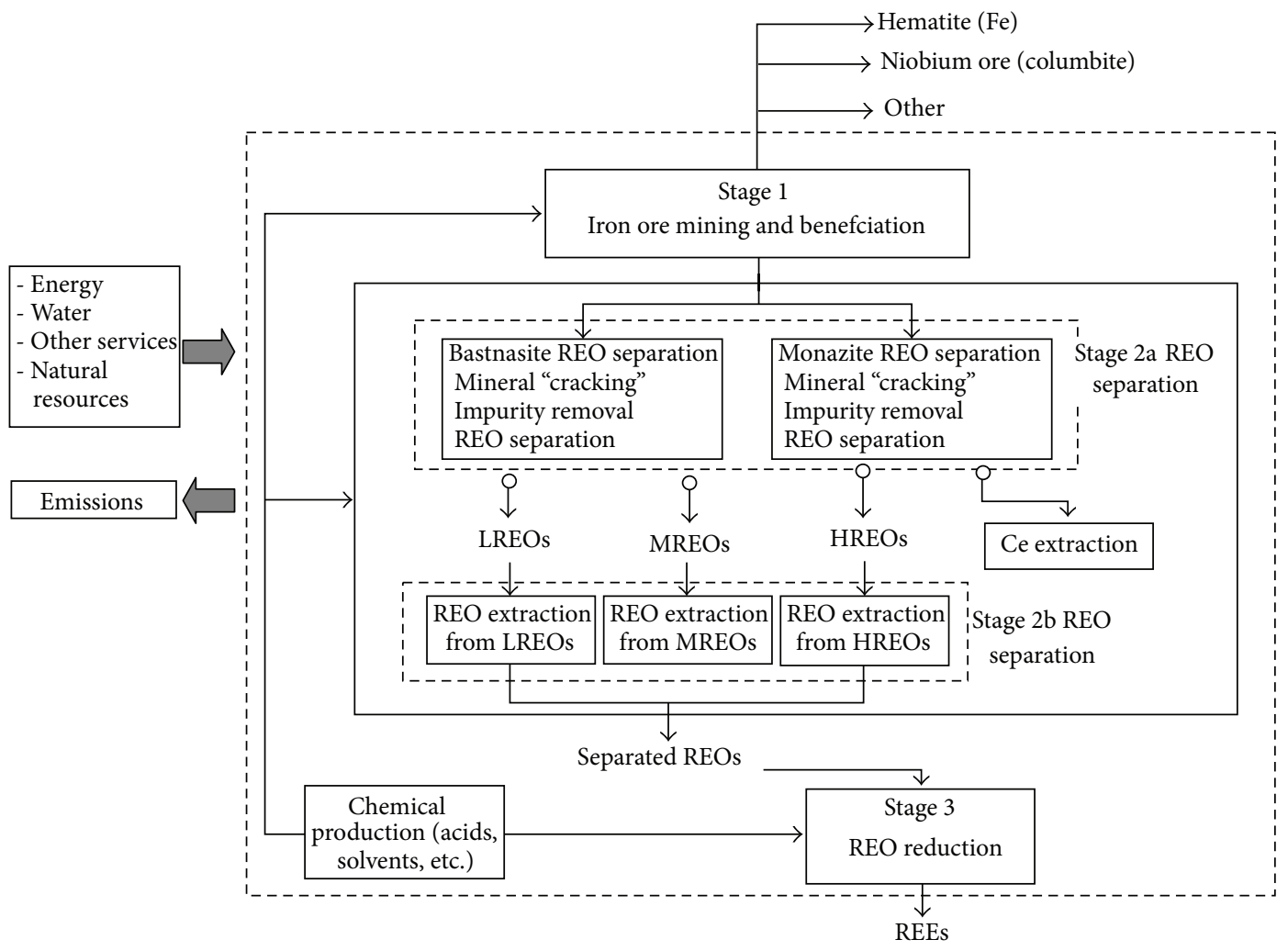

FIGURE 2: System boundary: mining and production of RE metals in China.

REEs usually have very small differences in solubility and complex formation and hence their separation can be difficult [22]. Thus, separation processes are often chemically intensive using ion exchange methods, solvent extraction, or fractional crystallization. The average recovery rate from $\mathrm{RE}$ containing ores is extremely low at $10 \%$ [24]. This is compounded by the low grade of REO in mined minerals at Bayan Obo (around 6\% [23]). Thus, the net recovery is about $0.6 \%$ and results in high resource inputs (electricity, acids, water and resources expended in production) as well as huge amounts of waste that can be toxic with potential damage to the ecosystem.

A representative system of extraction and production in Bayan Obo is shown in Figure 2. This representation is used as the system boundary for this LCA study and is explained briefly.

2.2. Stage 1: Mining and Beneficiation. Bayan Obo mineral Fe-REO-Nb deposit in China is the source of both ironore and RE containing minerals bastnasite and monazite. In separating the concentrates of bastnasite and monazite, a combination of separation processes (after grinding) are used including wet-magnetic separation and froth floatation. Since mining and beneficiation are established technologies, data is mostly based on our previous studies in mining and beneficiation [31,32].
2.3. Stage 2: Purification and Separation of REO. The concentrates of bastnasite and monazite (approximately $85 \%$ concentration by weight within the slurry [24]) from mining and beneficiation separately undergo further processing (shown as Stage 2a in Figure 2). This stage purifies and separates the light, medium, and heavy oxide groups using mineral cracking, acid leaching, impurity removal, and precipitation. While Stage 2a processes are similar for both concentrates, due to the substantial amount of radioactive elements in monazite (together thorium and uranium account about $6.5 \%$ of monazite) and phosphorus (phosphorus oxide accounts about $28 \%$ of monazite), the monazite processing is more energy and chemical intensive than bastnasite.

The extraction of RE oxide groups from both bastnasite and monazite produces cerium and separate streams of light, medium, and heavy RE oxides. The separated streams are further processed to produce the individual REOs. To extract the individual REOs, the oxide groups are subject to multistage extraction process using extractants in acidic medium. LREO separation involves 22 stages: 8 for extraction, 8 for scrubbing, and 6 for stripping [33]. MREOs have 29 extraction stages and 44 scrubbing stages [34]. Currently heavy RE oxides are separated by using ion exchange process with reagent impregnated resins [35].

2.4. Stage 3: Reduction of REEs. The industrial reduction to REEs from light REOs (La, Nd) including mischmetal 
TABLE 1: Bayan Obo iron ore composition and relative economic value of coproducts.

\begin{tabular}{lcccc}
\hline Commodity & $\begin{array}{c}\text { Fraction in Bayan } \\
\text { Obo deposit, } \%\end{array}$ & $\begin{array}{c}P_{c} \text { - Price per tone*, } \\
\text { US\$ }\end{array}$ & $\begin{array}{c}C_{c} \text { - Normalised } \\
\text { fraction, \% }\end{array}$ & $\begin{array}{c}X_{c}-\text { Share in } \\
\text { economic value, } \%\end{array}$ \\
\hline Iron ore (hematite) & 33 & 120.35 & 84.33 & 2.87 \\
RE oxides $\left(\mathrm{RE}_{x} \mathrm{O}_{y}\right)$ & 6 & 215400.00 & 15.33 & 93.31 \\
Niobium ore $($ columbite $)$ & 0.13 & 41000.00 & 0.33 & 3.82 \\
Fluorite $\left(\mathrm{CaF}_{2}\right)$ & 2 & - & - & 0 \\
Thorium oxide $\left(\mathrm{ThO}_{2}\right)$ & 0.16 & - & - & 0 \\
Phosporus oxide $\left(\mathrm{PO}_{4}\right)$ & 0.86 & - & - & 0 \\
Rest & 57.85 & - & - & 0 \\
\hline
\end{tabular}

* Prices are shown for the year 2009-2010. Prices estimated for iron ore [11], REO [12], and niobium ore [13].

(which are a mixture of light lanthanide metals) uses fusedsalt electrolysis (fused salt process is used when the reactivity of the metal does not allow electrowinning from aqueous solutions).

For MREEs and HREEs, metallothermic process using electrolysis from an aqueous solution or simple carbon based pyrometallurgy is employed due to the high electropositive nature of RE elements in these groups [36].

Processes for disposing toxic and other waste from the mining and processing are not considered in this study.

\section{LCA Study Methodology and Assumptions}

The principal goal of this study is to investigate the cradle-togate energy use (assessed as electricity use, heating fuel use, and total nonrenewable energy use), water use, and global warming impact of REEs produced in Bayan Obo, China. It is envisaged that the impact data of REEs created in this study could provide a basis for constructing and comparing impact profiles of rare earth based products.

On defining the scope of this study, the system boundary definition for ascertaining the impact is shown in Figure 2 and is explained in Section 2.2. Other topics of scope such as allocation, data sources, and uncertainty treatment are discussed below. Results of impact assessment are given in Section 4.

One aspect of scope that is given careful attention is the allocation of impacts. Normally, extraction of REEs is a multifunctional product system, meaning a number of outputs as saleable products are produced at the different stages of production. For instance, in Bayan Obo mining operation, hematite, niobium, and RE containing ores are produced as saleable coproducts of mining. The separated RE containing ore is then processed into saleable REOs or can be further reduced to produce individual REEs. Thus, properly allocating from "cradle to gate" (i.e., from mining to when REOs or reduced REEs are sold) is important.

Allocation among the coproducts uses both mass fractions (i.e., physical relationship) as well as an economic model. In fact, while mass-based allocation is sufficient as recommended by ISO 14044 [37], an additional economic model that combines mass and price basis (market value) is proposed here. This model reflects the underlying causality between economic reasons for producing coproducts (i.e., REEs from iron ore extraction) and their environmental impact as noted by [38]. It has also been suggested that economic allocations may be suited for coproducts that vary in prices [39] as is the case for REOs.

At Stage 1 iron ore mining (see Figure 2), three economically significant commodities (coproducts) are mined: hematite (FeO), columbite (niobium ore), and REO bearing ore (i.e., bastnasite and monazite minerals). Mass-based allocation uses the mass fractions of each product (see Table 1).

Economic allocation among these ores is performed on the basis of share of contribution of each product according to (1), where $C_{c}, P_{c}$, and $X_{c}$ are, respectively, the mass fraction, price, and computed environmental share of commodity $c$. Mass allocation uses $C_{c}$ as the basis. Share of allocation for each of the mined coproducts is shown in Table 1. The mass fractions $\left(C_{c}\right)$ are adjusted (normalized) across the economically valuable ores (iron ore, REO, and niobium):

$$
X_{c}=\frac{P_{c} * C_{c}}{\sum_{c}\left(P_{c} * C_{c}\right)} .
$$

In Stages $2 \mathrm{a}$ and $2 \mathrm{~b}$, the plant produces a mixture of REOs as coproducts. This would require calculation of impact that can be assigned to each of the individual REOs. A combined mass and economic allocation model similar to Stage 1 is developed and applied for this as described by the following equations:

$$
\begin{gathered}
C_{i}=c_{b} b_{i}+c_{m} m_{i}, \\
X_{i}=\frac{P_{i} * C_{i}}{\sum_{i}\left(P_{i} * C_{i}\right)} .
\end{gathered}
$$

In (2), the average mass composition $\left(C_{i}\right.$, used for mass-based allocation) of $\mathrm{REO}_{i}$ is determined using itsmass composition in bastnasite $\left(b_{i}\right)$ and monazite $\left(m_{i}\right)$ weighted according to the ratio of bastnasite $\left(c_{b}\right)$ and monazite $\left(c_{m}\right)$ processed. The proportion of bastnasite and monazite in Bayan Obo mineral deposit is taken as $3: 1$, respectively, with each containing $60 \%$ of RE oxides [40].

Equation (3) computes the share of the environmental burden $\left(X_{i}\right)$ using price per $\mathrm{kg}\left(P_{i}\right)$ of $\mathrm{REO}_{i}$ as the weighting factor normalised over all REOs. This way, both mass and economic proportions are combined to derive the final allocation given to each REO. 
TABLE 2: Share of environmental impact allocated for REOs.

\begin{tabular}{|c|c|c|c|c|c|c|c|}
\hline REE & REO & $i$ & $b_{i}, \%$ & $m_{i}, \%$ & $C_{i}, \%$ & $P_{i}, \mathrm{US} \$ / \mathrm{kg}$ & $X_{i}, \%$ \\
\hline Lanthanum & $\mathrm{La}_{2} \mathrm{O}_{3}$ & $\mathrm{La}$ & 23.00 & 23.00 & 23.00 & 13.00 & 7.75 \\
\hline Cerium & $\mathrm{CeO}_{2}$ & $\mathrm{Ce}$ & 50.00 & 46.00 & 49.00 & 12.00 & 15.24 \\
\hline Praseodymium $(+3)$ & $\operatorname{Pr}_{6} \mathrm{O}_{11}$ & $\operatorname{Pr}$ & 6.20 & 5.00 & 5.90 & 95.00 & 14.53 \\
\hline Neodymium & $\mathrm{Nd}_{2} \mathrm{O}_{3}$ & $\mathrm{Nd}$ & 18.50 & 19.00 & 18.63 & 77.00 & 37.18 \\
\hline Promethium & $\mathrm{Pm}_{2} \mathrm{O}_{3}$ & Pm & - & - & 0.00 & 0.00 & 0.00 \\
\hline Samarium & $\mathrm{Sm}_{2} \mathrm{O}_{3}$ & $\mathrm{Sm}$ & 0.80 & 3.00 & 1.35 & 23.50 & 0.82 \\
\hline Europium & $\mathrm{Eu}_{2} \mathrm{O}_{3}$ & $\mathrm{Eu}$ & 0.20 & 0.10 & 0.18 & 2150.00 & 9.75 \\
\hline Gadolinium & $\mathrm{Gd}_{2} \mathrm{O}_{3}$ & Gd & 0.70 & 1.70 & 0.95 & 75.00 & 1.85 \\
\hline Terbium & $\mathrm{Tb}_{4} \mathrm{O}_{7}$ & $\mathrm{~Tb}$ & 0.10 & 0.16 & 0.12 & 1750.00 & 5.22 \\
\hline Dysprosium & $\mathrm{Dy}_{2} \mathrm{O}_{3}$ & Dy & 0.10 & 0.50 & 0.20 & 975.00 & 5.05 \\
\hline Holmium & $\mathrm{Ho}_{2} \mathrm{O}_{3}$ & Ho & 0.00 & 0.00 & 0.00 & - & 0.00 \\
\hline Erbium & $\mathrm{Er}_{2} \mathrm{O}_{3}$ & Er & 0.00 & 0.13 & 0.03 & 77.00 & 0.06 \\
\hline Thulium & $\mathrm{Tm}_{2} \mathrm{O}_{3}$ & $\operatorname{Tm}$ & 0.00 & 0.00 & 0.00 & - & 0.00 \\
\hline Ytterbium & $\mathrm{Yb}_{2} \mathrm{O}_{3}$ & $\mathrm{Yb}$ & 0.00 & 0.06 & 0.02 & 69.12 & 0.03 \\
\hline Lutetium & $\mathrm{Lu}_{2} \mathrm{O}_{3}$ & $\mathrm{Lu}$ & - & - & 0.00 & - & 0.00 \\
\hline Scandium & $\mathrm{Sc}_{2} \mathrm{O}_{3}$ & $\mathrm{Sc}$ & - & 0.04 & 0.01 & 7200.00 & 1.87 \\
\hline Yttrium & $\mathrm{Y}_{2} \mathrm{O}_{3}$ & $\mathrm{Y}$ & 0.00 & 2.00 & 0.50 & 50.00 & 0.65 \\
\hline
\end{tabular}

References used: $b_{i}-[14] ; m_{i}-[1], \mathrm{Sc}_{2} \mathrm{O}_{3}-[15] ; P_{i}-[16], \mathrm{Sm}_{2} \mathrm{O}_{3}, \mathrm{Yb}_{2} \mathrm{O}_{3}-[17]$.

The values of pertinent parameters in (2) and (3) used in calculating the share of the environmental burden assigned to the REOs are given in Table 2. References used appear as notes in the table. The following REOs are not considered.

$\mathrm{Tm}$ and Ho are least abundant and are found with other rare earths such as gadolinite and other minerals containing rare earths, and $\mathrm{Lu}$ is the rarest of the rare earths [41]. Due to data availability, these are not considered here.

$\mathrm{Pm}$ is the only radioactive rare-earth metal of transition Group IIIb of the periodic table and not detected in nature [42]. It has a low period of half decay and its main route of production is artificial synthesis.

In Stage 3 REO-REE reduction, the mass fraction of individual REE present in the corresponding RE oxide is used for allocation.

The manner in which the above methods are used to calculate the impact allocated to REO or REE products, covering mining to production life cycle stages, is described below.

First, for the production of REO products, a reference flow for producing $1 \mathrm{~kg}$ mixture of REO products is considered at Stage 2. To obtain this, $166.7 \mathrm{~kg}$ of iron ore has to be mined (using average REE grade of $6 \%$ in the ore and REO recovery rate of $10 \%)$. Impact of mining this (Stage 1) is allocated among $\mathrm{Fe}, \mathrm{Nb}$, and $\mathrm{RE}$ containing concentrates (i.e., bastnasite and monazite) as described.

For Stage 2a (separation of REO groups), share of allocation derived for each REO is used (Table 2). In the case of Stage $2 b$ (separation of REOs from REO groups), the same model as used for Stage 2a is used, though it is normalized for the REOs for the oxides occurring within each group. Impact from mining to REO production is the sum of the Stages 1-2 for the fraction of REOs in the reference flow. Finally, the impact per $\mathrm{kg}$ of individual REO is calculated.
In deriving the allocation for each REE, the impact of REO-REE reduction stage is first assigned on a mass basis, that is, the mass fraction of individual REE present in the corresponding RE oxide. "Cradle to gate" impact per kilogram of individual REE is determined by adding the impact of corresponding REO and this stage.

Inventory data for the processes is obtained from publicly available information sources (cited appropriately under each section) and by estimation. These include review of technological processes for RE production and analogous processes, environmental data pertaining to materials and chemicals mainly from EcoInvent life cycle inventory (LCI) database [43], and other LCI databases combined with modeling and estimation. Table 3 provides the basic data for energy and water use at each stage from mining to REO extraction. The diverse sources of data require uncertainty analysis, such as Pedigree Matrix [44] combined with Monte Carlo simulation available in SimaPro software [45]. However, such analysis will be performed as a future extension of this study.

The major assumptions of this study include the following.

(a) Distance between mining pit and beneficiation plant and beneficiation and REO separation plant are assumed as $15 \mathrm{~km}$ and $30 \mathrm{~km}$, respectively. REO reduction and subsequent reduction to REE occur at the same place, that is, Bayan Obo Township.

(b) In separating REOs from monazite concentrates radioactive wastes can occur. Treatment of such waste can pose additional environmental effects including toxicity and soil and ground water contamination. The treatment processes of such waste are considered out of scope. 
TABLE 3: Life cycle inventory and impact of production stages for the production of $1 \mathrm{~kg}$ of RE oxide.

\begin{tabular}{|c|c|c|c|c|c|c|}
\hline \multirow{2}{*}{ Stage } & \multirow{2}{*}{ Process } & \multicolumn{2}{|c|}{ Energy consumption, $\mathrm{MJ}$} & \multirow{2}{*}{ Water consumption, $\mathrm{kL}$} & \multicolumn{2}{|c|}{ Environmental impact } \\
\hline & & Electricity & Heat energy & & $\begin{array}{l}\text { GHG emissions, } \\
\text { kg CO}{ }_{2} \text { eq. }\end{array}$ & $\begin{array}{c}\text { Resource } \\
\text { depletion, MJ } \\
\text { surplus }\end{array}$ \\
\hline Stage 1 & $\begin{array}{l}\text { Mining and } \\
\text { beneficiation }\end{array}$ & 4.64 & 10.11 & 3.24 & 3.95 & 5.46 \\
\hline \multirow[t]{2}{*}{ Stage $2 \mathrm{a}$} & $\begin{array}{l}\text { REO extraction } \\
\text { from bastnasite }\end{array}$ & 5.60 & 90.00 & 19.09 & 10.5 & 13.9 \\
\hline & $\begin{array}{l}\text { REO extraction } \\
\text { from monazite }\end{array}$ & 55.60 & 11.90 & 18.15 & 18.3 & 19.6 \\
\hline \multirow{3}{*}{ Stage $2 b$} & $\begin{array}{l}\text { Light REO } \\
\text { separation }\end{array}$ & 12.60 & 0 & 0.58 & 3.3 & 2.80 \\
\hline & $\begin{array}{l}\text { Medium REO } \\
\text { separation }\end{array}$ & 5.20 & 0 & 0.16 & 1.3 & 1.29 \\
\hline & $\begin{array}{c}\text { Heavy REO } \\
\text { separation }\end{array}$ & 15.50 & 0 & 8.52 & 5.5 & 5.57 \\
\hline
\end{tabular}

(c) Average grid-mix of electricity in China is $75 \%$ from coal power stations and the rest is from hydro [31].

(d) Purity range of REOs produced (to derive the life cycle inventory data) is $98.0 \%-99.9 \%$ associated with current production technology in China.

(e) A steady-state process with a constant rate of materials and energy flows is assumed.

(f) Chemical and other materials used in the processes are assumed to be imported from Europe and hence, the energy consumption for their production is mostly based on data taken from the European LCI databases $([43,45])$.

\section{Environmental Impact}

The life cycle inventory (LCI) of energy (both electricity and heat) and water consumption and corresponding global warming impact for mining and separating REOs (i.e. stages 1 and 2 in Figure 2 ) to produce $1 \mathrm{~kg}$ of mixed REOs are shown in Table 3. Assignment of impacts among products uses the allocation methods described already. The widely used Eco-indicator 99 impact assessment methodology [46] is used in selecting and computing the appropriate environmental damage indicators. SimaPro software [45] is used in deriving the indicator scores.

Two indicators selected for this study are GHG for global warming potential and resource depletion. Resource depletion is defined in the Eco-indicator 99 methodology report [46]. It is measured in terms of surplus energy (MJ) required to obtain the same quality of resource as they become depleted. The calculation of this indicator uses geostatistical models to analyse the concentration of a mining resource at a reference year followed by assumptions on future depletion rates. The somewhat arbitrary and limiting nature of assumptions and calculation makes this indicator useful only as a comparative measure (the methodology report in [46] provides more information). Nevertheless, in the absence of more objective indicators resource depletion is used here.

Examining Table 3, one can see that energy consumption and GHG emissions for the REO extraction (Stage 2a) are much more for monazite than bastnasite, due to the required additional separation of uranium, thorium, and phosphorous for the former. In Stage 2b, the impact is the highest for separation of HREOs due to ion exchange process used. While solvent extraction process is used for both LREOs and MREOs with the latter being more difficult, impact from LREO extraction is higher due to the higher mass contribution (1 kg mixed REOs contains about 96\% LREOs). Out of all the stages, Stage 2 a (REO extraction, see Table 3 ) has the most resource deletion of around $33.5 \mathrm{MJ}$ surplus

Impact for each of the separated REOs from Stages 1 and 2 is computed using both mass- and price-based allocation methods described in the previous section. Pricebased allocation of impact per kilogram of each REO is shown in Table 4.

Comparison of environmental impacts among the REOs shows that LREOs (La-Nd) have lower impact than the rest of the REOs with La and Ce being minimal within the LREO group. The impact for other REOs varies substantially and cannot be attributed to their classification as MREOs and HREOs.

The impacts assigned to REOs are influenced by the concentration and price; the lower the percentage concentration and the higher the price, the higher the share of impact per kg. Among the REOs, scandium oxide $\left(\mathrm{Sc}_{2} \mathrm{O}_{3}\right)$ has the highest $\mathrm{GHG}$ impact at $\sim 6,332 \mathrm{~kg}$ of $\mathrm{CO}_{2}$ eq. $/ \mathrm{kg}$ due to its very high price (USD 7,200 per kg) and very low occurrence $(0.01 \%)$. The next highest impact is for europium oxide $\left(\mathrm{Eu}_{2} \mathrm{O}_{3}\right)$ at $\sim 1,884 \mathrm{~kg}$ of $\mathrm{CO}_{2}$ eq. $/ \mathrm{kg}$. Its concentration is comparatively higher and price is lower than $\mathrm{Sc}_{2} \mathrm{O}_{3}$. Other notable high-impact REOs are terbium oxide $\left(\mathrm{Tb}_{4} \mathrm{O}_{7}\right.$, $1,539 \mathrm{~kg}$ of $\mathrm{CO}_{2}$ eq. $\left./ \mathrm{kg}\right)$ and dysprosium oxide $\left(\mathrm{Dy}_{2} \mathrm{O}_{3}\right.$, $857 \mathrm{~kg}$ of $\mathrm{CO}_{2} \mathrm{eq} / \mathrm{kg}$ ).

When mass-based allocation is used, a separated REO carries the same impact assigned to an RE group. This is due 
TABLE 4: Life cycle inventory and impact for the production of $1 \mathrm{~kg}$ RE oxides using price-based allocation.

\begin{tabular}{|c|c|c|c|c|c|c|}
\hline \multirow{2}{*}{ RE oxide } & \multirow{2}{*}{ Classification } & \multicolumn{2}{|c|}{ Energy consumption } & \multirow{2}{*}{ Water consumption, $\mathrm{kL}$} & \multicolumn{2}{|c|}{ Environmental impact } \\
\hline & & Electricity, MJ & Heat, MJ & & $\begin{array}{l}\text { GHG emissions, } \\
\mathrm{kg} \mathrm{CO}_{2} \text { eq. }\end{array}$ & $\begin{array}{c}\text { Resources } \\
\text { depletion, M) } \\
\text { surplus }\end{array}$ \\
\hline $\mathrm{La}_{2} \mathrm{O}_{3}$ & Light & 26.13 & 34.39 & 12.82 & 11.16 & 12.52 \\
\hline $\mathrm{CeO}_{2}$ & Light & 24.12 & 31.74 & 11.83 & 10.30 & 11.56 \\
\hline $\operatorname{Pr}_{6} \mathrm{O}_{11}$ & Light & 190.97 & 251.28 & 93.69 & 81.53 & 91.52 \\
\hline $\mathrm{Nd}_{2} \mathrm{O}_{3}$ & Light & 154.78 & 203.67 & 75.94 & 66.09 & 74.18 \\
\hline $\mathrm{Pm}_{2} \mathrm{O}_{3}$ & Medium & 0.00 & 0.00 & 0.00 & 0.00 & 0.00 \\
\hline $\mathrm{Sm}_{2} \mathrm{O}_{3}$ & Medium & 37.95 & 62.16 & 22.74 & 17.73 & 20.59 \\
\hline $\mathrm{Eu}_{2} \mathrm{O}_{3}$ & Medium & 3472.18 & 5686.98 & 2080.32 & 1622.04 & 1883.96 \\
\hline $\mathrm{Gd}_{2} \mathrm{O}_{3}$ & Heavy & 121.12 & 198.38 & 72.57 & 56.58 & 65.72 \\
\hline $\mathrm{Tb}_{4} \mathrm{O}_{7}$ & Heavy & 2826.83 & 4628.93 & 1718.02 & 1325.42 & 1538.92 \\
\hline $\mathrm{Dy}_{2} \mathrm{O}_{3}$ & Heavy & 1574.95 & 2578.98 & 957.18 & 738.45 & 857.40 \\
\hline $\mathrm{Ho}_{2} \mathrm{O}_{3}$ & Heavy & 0.00 & 0.00 & 0.00 & 0.00 & 0.00 \\
\hline $\mathrm{Er}_{2} \mathrm{O}_{3}$ & Heavy & 124.38 & 203.67 & 75.59 & 58.32 & 67.71 \\
\hline $\mathrm{Tm}_{2} \mathrm{O}_{3}$ & Heavy & 0.00 & 0.00 & 0.00 & 0.00 & 0.00 \\
\hline $\mathrm{Yb}_{2} \mathrm{O}_{3}$ & Heavy & 111.65 & 182.83 & 67.86 & 52.35 & 60.78 \\
\hline $\mathrm{Lu}_{2} \mathrm{O}_{3}$ & Heavy & 0.00 & 0.00 & 0.00 & 0.00 & 0.00 \\
\hline $\mathrm{Sc}_{2} \mathrm{O}_{3}$ & Heavy & 11630.4 & 19044.8 & 7068.42 & 5453.15 & 6331.55 \\
\hline $\mathrm{Y}_{2} \mathrm{O}_{3}$ & Heavy & 80.77 & 132.26 & 49.09 & 37.87 & 43.97 \\
\hline
\end{tabular}

TABLE 5: Life cycle inventory and impact for the production of $1 \mathrm{~kg}$ RE oxides using mass-based allocation.

\begin{tabular}{|c|c|c|c|c|c|}
\hline \multirow{2}{*}{ Classification } & \multicolumn{2}{|c|}{ Energy consumption } & \multirow{2}{*}{ Water consumption, $\mathrm{kL}$} & \multicolumn{2}{|c|}{ Environmental impact } \\
\hline & Electricity, MJ & Heat, MJ & & $\begin{array}{l}\text { GHG emissions, } \mathrm{kg} \\
\mathrm{CO}_{2} \text { eq. }\end{array}$ & $\begin{array}{c}\text { Resources } \\
\text { depletion, MJ } \\
\text { surplus }\end{array}$ \\
\hline Light REOs & 74.08 & 102.51 & 38.06 & 32.29 & 36.50 \\
\hline Medium REOs & 66.68 & 102.51 & 37.64 & 30.29 & 34.99 \\
\hline Heavy REOs & 76.98 & 102.51 & 37.64 & 34.49 & 39.27 \\
\hline
\end{tabular}

to the allocation being normalized by group and derived on a per $\mathrm{kg}$ basis. Table 5 shows the mass-based impact by RE group. Here, the values in the table are affected by Stage $2 b$, which is particular to the groups. Hence, MREOs, being lower than others, have lower inventory and impact values.

A comparative GHG profile of REOs with allocations based on price and mass is shown in Figure 3. As noted, GHG allocation using mass-based allocation is the same for REOs in the same group.

Separated REOs are further processed in a reduction stage to extract the individual REEs. This study assumes that the reduction plants are located in Bayan Obo and no or minimal transport takes place. An average impact is calculated for electrolytic process (for LREEs) and metallothermic process (HREEs and MREEs) based on [47] and [48], respectively. Thus, the impact calculated for this stage alone is affected by the process yield of $80 \%$ for LREEs and $95 \%$ for other REEs; the impacts for reduction are, respectively, 5.64 and $5.04 \mathrm{~kg}$ of $\mathrm{CO}_{2}$ eq./ $/ \mathrm{kg}$ of REE.

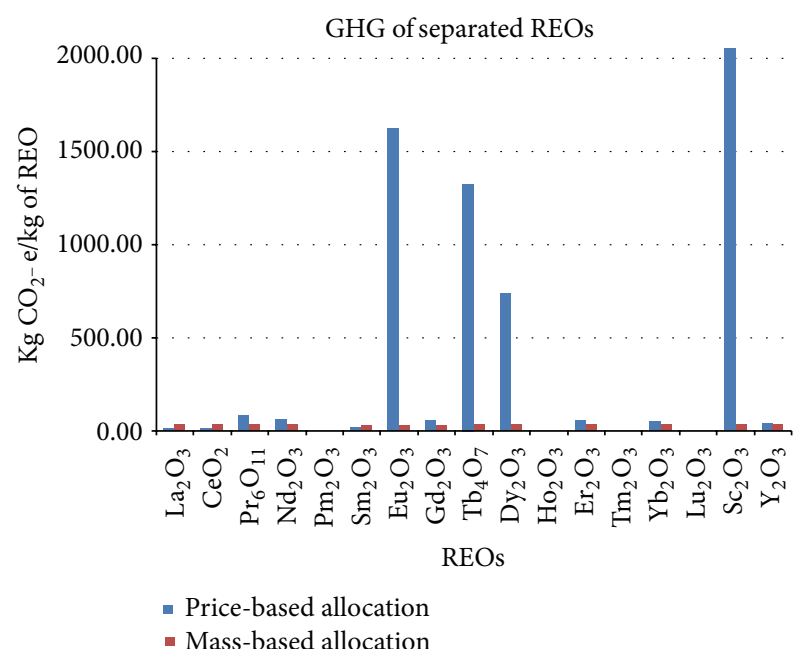

FIGURE 3: Comparative GHG of rare earth oxides for mass- and price-based allocations. 


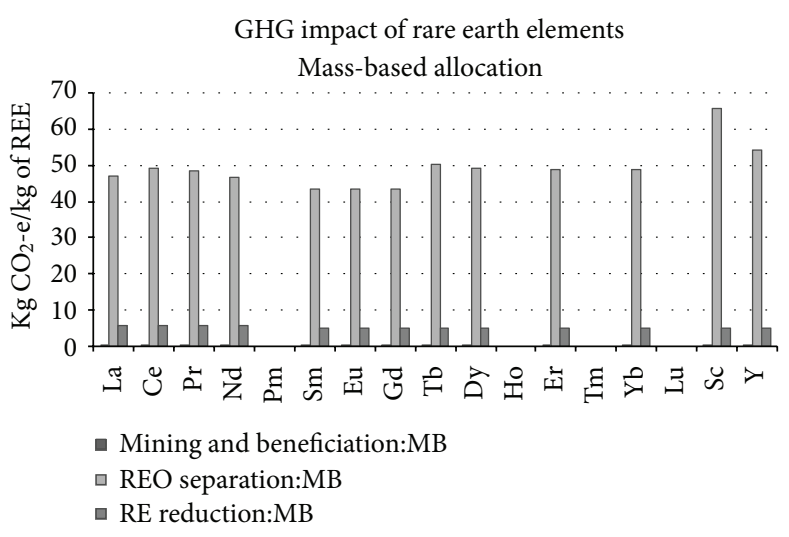

(a)

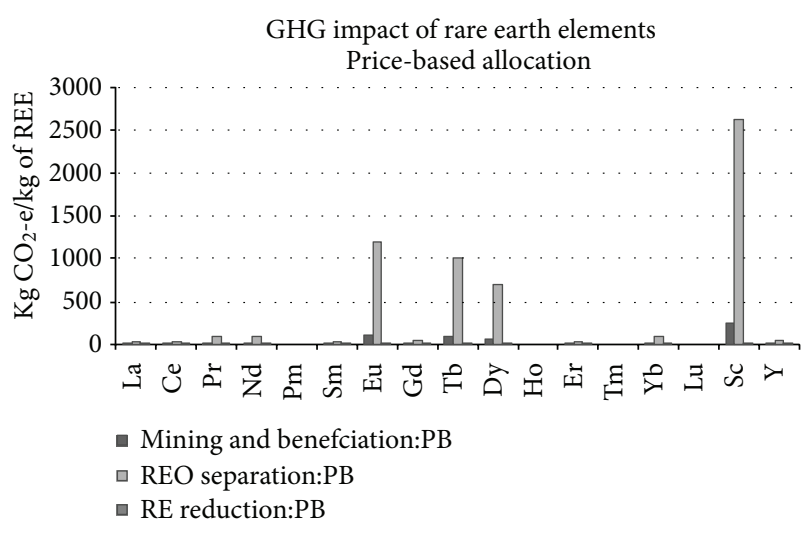

(b)

Figure 4: Cradle-to-gate GHG emissions of rare earth elements.

\section{Discussion}

GHG emissions from "cradle-to-gate" life cycle stages of production (i.e., mining, REO separation, and REE reduction) based on mass- and price-based allocation for extracting $1 \mathrm{~kg}$ of individual REE are displayed in Figure 4. Massbased approach allocates more emissions to more abundant elements, though when computed per kilogram of REE, the mass proportion becomes insensitive. Thus, the factor that influences the comparative allocation is the energy and materials expended (differs between RE groups) and the extractable mass of REE from its oxide. This is apparent in Figure 4(a) where Sc has the highest impact followed by Y. The extractable mass of REE from the 25 oxide for these two is, respectively, $65 \%$ and $78 \%$ compared to others that are in the range of $81 \%-85 \%$.

Unlike mass-based allocation, price-based allocation model proposed here uses both mass concentrations in mineral and price. The comparative impacts allocated are hence influenced by: (1) energy and materials consumed at each stage; (2) extractable mass of REE in the minerals, that is concentrations in bastnasite and monazite and mass proportion in the respective oxides; and (3) price used in calculating the share of environmental burden to be allocated.

In this model, scandium, europium, terbium, and dysprosium have relatively very high impact (Figure 4(b)). The corresponding REOs of these are high too for reasons cited in the last section. In reducing them to REEs, a further increase in the case of scandium occurs due to its lower extractable mass from its oxide of $\sim 65 \%$ compared to $\sim 86 \%$ for europium, $\sim 85 \%$ for terbium, and $\sim 87 \%$ for dysprosium. Thus, to produce $1 \mathrm{~kg}$ of Sc would require $30 \%$ more $\mathrm{Sc}_{2} \mathrm{O}_{3}$ than other oxides. Additionally, $\mathrm{Sc}_{2} \mathrm{O}_{3}, \mathrm{~Tb}_{4} \mathrm{O}_{7}$, and $\mathrm{Dy}_{2} \mathrm{O}_{3}$ are HREOs, the separation of which requires more energy. Economic allocation is influenced by price fluctuations. While the prices of REOs have been volatile dropping as much as $40 \%-60 \%$ in 2011-12 [16], nevertheless, the comparative prices of the above four high impact REOs have been consistently higher than other REOs. Thus, they remain the high impact rare earths relative to others.
In any case, the impact of individual REEs can vary with price fluctuations.

Comparison of the two allocation methods shows that mass-based allocation is not sensitive to the scarcity of the rare earth in the mineral (per kilogram basis). The suggested allocation based on combination mass, concentration, and price shows such sensitivity; for example, allocated GHG emissions for low concentration REEs and those that are highly priced tend to be high.

Further, Bayan Obo is unique as an iron ore mine that also produces rare earths, and though similar, Mountain Pass does not produce iron ore or niobium. This means that in this case only part of the total energy and environmental impacts associated with mining stage is assigned to rare earths. While the impact of this stage may be smaller than other stages, this peculiarity of the model has to be recognised.

\section{Conclusion}

This study has in some detail investigated the cradle-to-gate GHG impact of a rather complex route of producing REEs starting from extraction of rare earth minerals, separation of oxides, and final reduction of REEs.

Both mass- and price-based allocation models have been employed in estimating the impact. The former is only sensitive to the extractable mass concentrations, whereas price based allocation model proposed in this study is additionally sensitive to price. Thus, where the price of coproducts of product systems varies widely as in the case of rare earths, it tends to amplify the impact of highly priced rare earths that have lower concentrations. This information can be useful in focussing efforts to improve process efficiency and recycling to increase supply.

Recycling is an attractive pathway given the increasing prices of rare earths (while 2011-12 prices were down, they are generally higher than 2010 prices) combined with the recent clamp down on exports by China. The route to recycling can be closed-loop, meaning the recovery of the original 
RE alloys with minimum loss of property for similar applications. Such direct recycling, however, has its challenges in collecting, sorting, separating components, and finding suitable processes. An open-loop recycling, where REEs can be recovered from alloys for use in other applications, is also viable. Investigation of GHG impacts of the various routes to recycling is planned as the extension of this study.

An additional concern is the impact on the environment from processing waste. In particular, the large amount of tailings is produced in beneficiation and extraction of bastnasite and monazite concentrates. Tailings of both of these, monazite in particular, contain naturally occurring radionuclides and the release of this to the environment by air, wastewater, and rain leaching can have longer-term health effects to humans and ecosystems of the local environment. An assessment of these and other impacts from waste processing and disposal is seen as supplementing this study.

\section{Conflict of Interests}

The authors declare that there is no conflict of interests regarding the publication of this paper.

\section{References}

[1] Australian Industry Commission, New and Advanced Materials, Australian Government Publishing Service, Melbourne, Australia, 1995.

[2] U.S. Geological Survey, "Rare Earth Elements-Critical Resources for High Technology," Fact Sheet 087-02, 2002, http://pubs .usgs.gov/fs/2002/fs087-02/.

[3] U.S. Geological Survey, "Mineral Commodity SummariesRare Earths," 2008, http://minerals.usgs.gov/minerals/pubs/ commodity/rare_earths/mcs-2008-raree.pdf.

[4] HEFA Rare Earth Canada Co. Ltd, Rare Earth products by element, http://www.baotou-rareearth.com/.

[5] U.S. Department of Energy, "Critical Materials Strategy," December 2011, http://energy.gov/pi/office-policy-and-international-affairs/downloads/2011-critical-materials-strategy.

[6] S. Gorman, "As hybrid cars gobble rare metals, shortage looms," Reuters, 30th August 2009, http://www.reuters.com/article/ GCA-GreenBusiness/idUSTRE57U02L20090831.

[7] S. Gorman, "California mine digs in for, "green" gold rush," Reuters, 30th August 2009, http://www.reuters.com/article/ idUSTRE57U02I20090831? sp=true.

[8] A. Pasternack, "China Tightens Grasp on Rare Earth Metals Vital for Green Technologies," Treehugger (Business \& Politics), August 2009, http://www.earth-stream.com/outpage.php?s $=18 \&$ \&id $=201861$.

[9] D. Bauer, D. Diamond, J. Li, D. Sandalow, P. Telleen, and B. Wanneret, "Critical Materials Strategy, US Department of Energy," 2010, http://energy.gov/sites/prod/files/edg/news/documents/criticalmaterialsstrategy.pdf.

[10] T. E. Graedel, "On the future availability of the energy metals," Annual Review of Materials Research, vol. 41, pp. 323-335, 2011.

[11] “Iron Ore Monthly Price," November 2012, http://www.indexmundi.com/commodities/?commodity=iron-ore\&months $=12$.

[12] D. Kingsnorth, "Rare earths: is supply critical in 2013?" in Proceedings of the Critical Minerals Conference Perth (AusIMM '13),
Curtin Graduate School of Business; Curtin University \& Industrial Minerals Company of Australia Pty Ltd, Western, Australia, June 2013.

[13] U.S. Geological Survey, "Niobium (Columbium) and Tantalum Statistics and Information," Mineral Commodity SummariesNiobium (Columbium) 2012, http://minerals.usgs.gov/pubs/ commodity/niobium/mcs-2012-niobi.pdf.

[14] U.S. Geological Survey, Rare Earths Statistics and Information 2010, Minerals Yearbook 2010-Rare Earth Contents of Major and Potential Source Minerals, 2010, http://minerals.usgs.gov/ minerals/pubs/commodity/rare_earths/mybl-2010-raree.xls.

[15] C. Yan, J. Jia, C. Liao, S. Wu, and G. Xu, "Rare earth separation in China," Tsinghua Science and Technology, vol. 11, no. 2, pp. 241-247, 2006.

[16] MineralPrices, December 2012, http://www.mineralprices .com/.

[17] AsianMetal, "Rare Earth Prices," December 2012, http://www .asianmetal.com/price/initPriceListEn.am?priceFlag=8\&productInfoIMG=PrNd+Mischmetal\%E3\%80\%8299\%EF\%BC\%85 min+Nd+75\%EF\%BC\%85+China $\%$ E3\%80\%82RMB $\% 2$ FMT\#.

[18] The China Post, "China will limit its exports of rare earth metals, official says," 3rd August 2009, http://www.chinapost .com.tw/business/asia/b-china/2009/09/03/223211/China-will .htm.

[19] W. M. Morrison and R. Tang, "China's Rare Earth Industry and Export Regime: Economic and Trade Implications for the United States," Congressional Research Service 7-5700 R42510, April 2012, http://www.fas.org/sgp/crs/row/R42510.pdf.

[20] ChinaDaily, "China announces rare earth export quotas," July 2011, http://www.chinadaily.com.cn/china/2011-07/14/content 12906607.htm.

[21] X. Du and T. E. Graedel, "Global in-use stocks of the rare earth elements: a first estimate," Environmental Science and Technology, vol. 45, no. 9, pp. 4096-4101, 2011.

[22] A. M. Helmenstine, "Rare Earth Properties," 2009, http://chemistry.about.com/od/elementgroups/a/rareearths.htm.

[23] L. J. Drew, M. Qingrun, and S. Weijun, "The Bayan Obo ironrare-earth-niobium deposits, Inner Mongolia, China," LITHOS, vol. 26, no. 1-2, pp. 43-65, 1990.

[24] C. W. Sinton, "Study of the Rare Earth Resources and Markets for the Mt," Weld Complex for Lynas Corporation. BCC Research, Washington, DC, USA, 2008, http://www.lynas-corp .com/content/upload/files/press_releases/BCC_FINAL_REPORT .pdf.

[25] R. Will, A. Eric, and N. Takei, "Chemical Economics Handbook-Rare Earth Minerals and Products," SRI Consulting, Menlo Park, Calif, USA, 2010, http://www.sriconsulting.com/ CEH/Public/Reports/765.5000/.

[26] Y. Kanazawa and M. Kamitani, "Rare earth minerals and resources in the world," Journal of Alloys and Compounds, vol. 408-412, pp. 1339-1343, 2006.

[27] G. X. Xing and H. M. Chen, "Environmental impacts of metal and other inorganics on soil and groundwater in China," in Soils and Groundwater Pollution and Remediation: Asia, Africa, and Oceania, P. M. Huang and I. K. Iskandar, Eds., pp. 167-200, CRC Press, 1999.

[28] S. Zhang and X.-Q. Shan, "Speciation of rare earth elements in soil and accumulation by wheat with rare earth fertilizer application," Environmental Pollution, vol. 112, no. 3, pp. 395405, 2001. 
[29] MolyCorp, "Mountain Pass Production," 2011, http://www .molycorp.jp/about-us/current-future-production/.

[30] Geoscience Australia, "Rare Earth Production and Exports," December 2012, http://www.ga.gov.au/minerals/mineral-resources/rare-earth-elements.html.

[31] S. Ramakrishnan and P. Koltun, "Global warming impact of the magnesium produced in China using the Pidgeon process," Resources, Conservation and Recycling, vol. 42, no. 1, pp. 49-64, 2004.

[32] A. Tharumarajah and P. Koltun, "Is there an environmental advantage of using magnesium components for light-weighting cars?" Journal of Cleaner Production, vol. 15, no. 11-12, pp. 10071013, 2007.

[33] C. A. Morais and V. S. T. Ciminelli, "Process development for the recovery of high-grade lanthanum by solvent extraction," Hydrometallurgy, vol. 73, no. 3-4, pp. 237-244, 2004.

[34] L. Wenli, G. D. '. Ascenzo, R. Curini et al., "Simulation of the development automatization control system for rare earth extraction process: combination of ESRECE simulation software and EDXRF analysis technique," Analytica Chimica Acta, vol. 417, no. 1, pp. 111-118, 2000.

[35] C. Liao, C. Yan, and J. Jia, "A Novel Solvent Extraction System for Tm, Yb and Lu," China Patent CN, 98100226.9, 2008, http:// www.sciencedirect.com/science/article/pii/S1007021406701833.

[36] P. F. Duby, Kirk-Othmer Encyclopedia of Chemical Technology, John Wiley \& Sons, 2005.

[37] International Standards Organisation, "Environmental management-Life cycle assessment-Requirements and guidelines," ISO 14044, 2006.

[38] K. Kodera, Analysis of allocation methods of bioethanol LCA, Internship at CML [M.S. thesis], Faculty of Earth and Life Science, Leiden University, Leiden, The Netherlands, 2007.

[39] F. Ardente and M. Cellura, "Economic allocation in life cycle assessment: the state of the art and discussion of examples," Journal of Industrial Ecology, vol. 16, no. 3, pp. 387-398, 2012.

[40] J. Ren, S. Song, A. Lopez-Valdivieso, and S. Lu, "Selective flotation of bastnaesite from monazite in rare earth concentrates using potassium alum as depressant," International Journal of Mineral Processing, vol. 59, no. 3, pp. 237-245, 2000.

[41] Development Corp., Rare Earth Elements, http://www.candldevelopment.com/rare_earth_detail.htm.

[42] C. R. Hammond, The Elements, Handbook of Chemistry and Physics, CRC press, 81st edition, 2000.

[43] EcoInvent Centre, http://www.ecoinvent.org/database/.

[44] B. P. Weidema and M. S. Wesnæs, "Data quality management for life cycle inventories-an example of using data quality indicators," Journal of Cleaner Production, vol. 4, no. 3-4, pp. 167-174, 1996.

[45] Pre Consultants, 2011, http://www.pre.nl/.

[46] Pre Consultants, "A Damage oriented method for Life Cycle Assessment, Methodology Report," 2nd edition, 2000, http:// teclim.ufba.br/jsf/indicadores/holan\%20ecoindicator\%2099.pdf.

[47] E. S. Shedd, J. D. Marchant, and T. A. Henrie, "Electrowinning and tapping of lanthanum metal," Bureau of Mines Report of Investigations 6882, U.S. Department of the Interior, Washington, DC, USA, 1966.

[48] R. A. Sharma, "Mettalothermic reduction of rare earth chlorides," US Patent 4680055, General Motors Corporation, http:// www.freepatentsonline.com/4680055.pdf. 

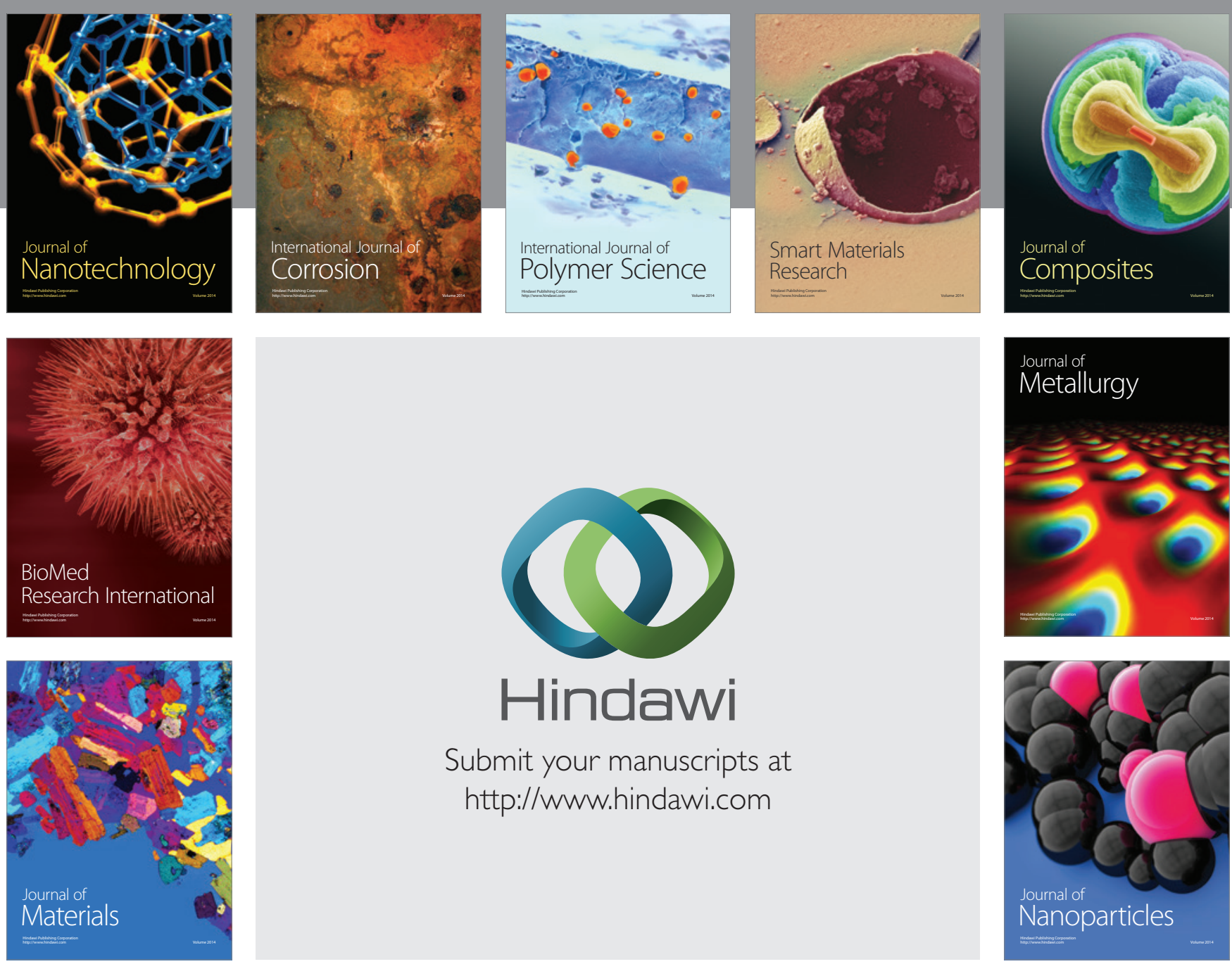

Submit your manuscripts at http://www.hindawi.com
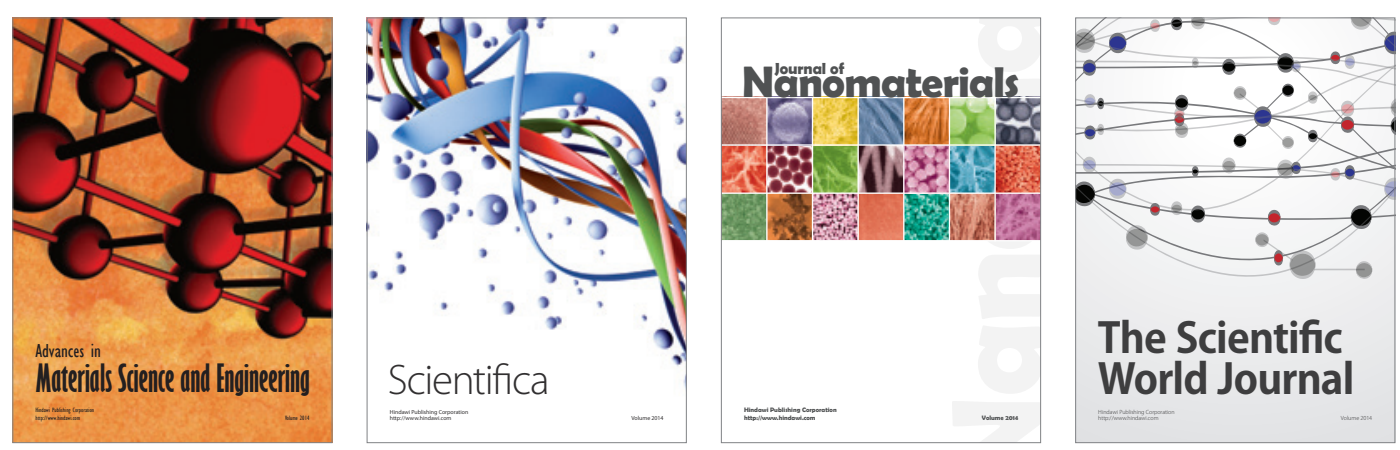

\section{The Scientific World Journal}
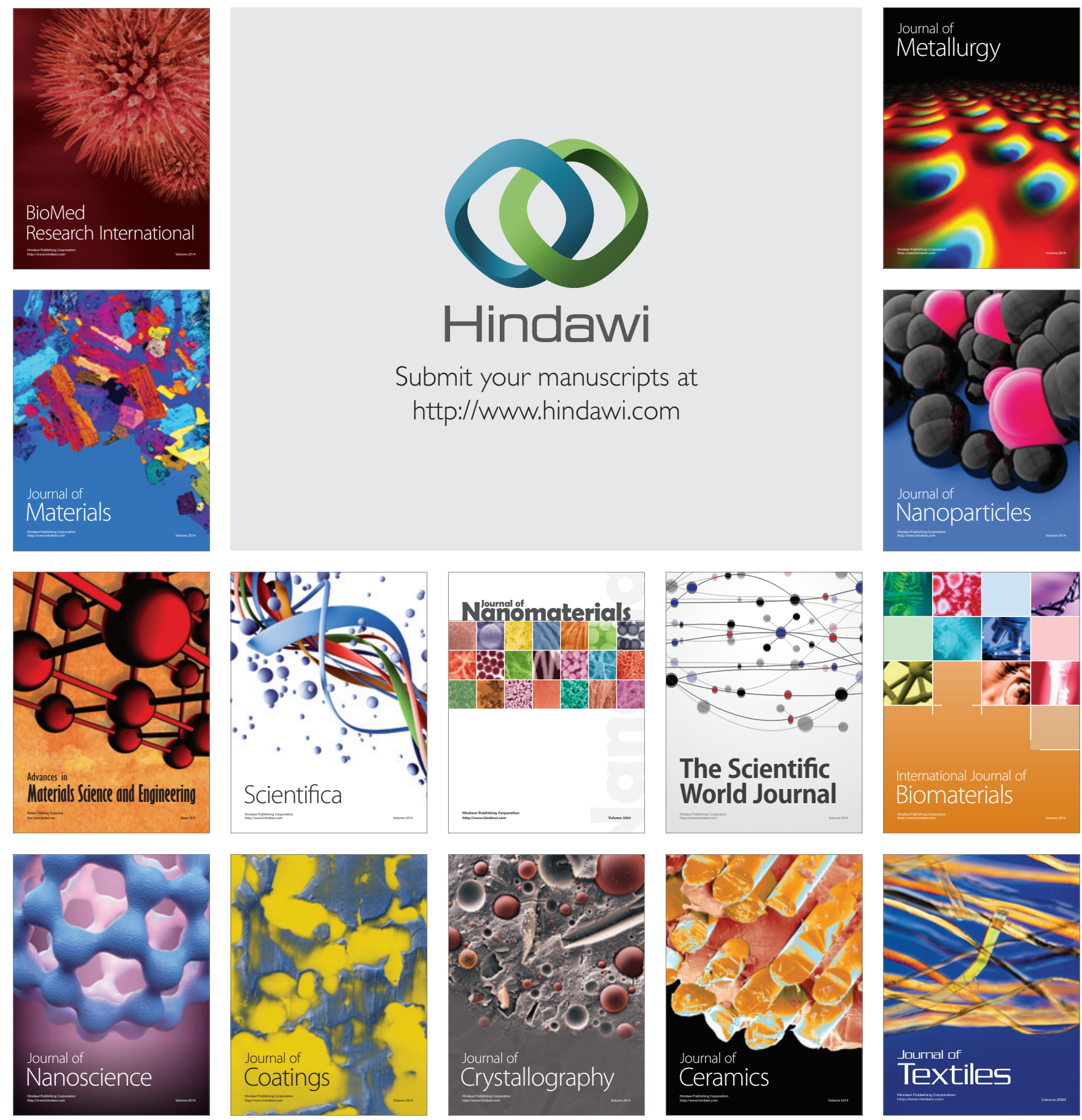